Research

\title{
Ex Ante Scale Dynamics Analysis in the Policy Debate on Sustainable Biofuels in Mozambique
}

\author{
Marc Schut $^{1}$, Cees Leeuwis ${ }^{1}$ and Annemarie van Paassen ${ }^{1}$
}

\begin{abstract}
In this paper, we explore how ex ante scale dynamics analysis can contribute to better understanding of interactions between scales and levels, and how these interactions influence solution space in policy processes. In so doing, we address opportunities and challenges of conducting ex ante scale dynamics analysis as part of an action-oriented social science research approach that seeks to enhance its contribution to more scale-sensitive policy development. The policy debate on sustainable biofuels in Mozambique provides the empirical context in which we analyze interactions across administrative, institutional, and economic scales and levels, and how these interactions influence the space in which policy solutions can be explored and designed. On the basis of the analysis, we conclude that ex ante scale dynamics analysis can contribute to: (1) increasing awareness of interactions between scales and levels, and their implications for policy, (2) identifying immediate and potential matches and mismatches between scales and levels, and developing (adaptive) capacity to address them, and (3) identifying stakeholders and their scale- and level-related interests that can provide the basis for collaborative multi-stakeholder learning. Consequently, ex ante scale dynamics analysis can provide an important contribution to balancing and harmonizing interactions across different scales and levels, from which innovative and scale-sensitive policy responses can emerge. As part of an actionoriented, social science research approach, careful attention needs to be paid to processes of scale and level inclusion and exclusion when conducting scale dynamics analysis.
\end{abstract}

Key Words: action-oriented research; biofuels; ex ante scale dynamics analysis; Mozambique; policy processes; scale and level; sustainability

\section{INTRODUCTION}

In the context of globalization, there is increasing awareness that sustainable policy solutions to complex environmental problems need to be explored across the boundaries of countries and continents, and across different administrative, institutional, economic, and political scales and levels (Cumming et al. 2006, Smith et al. 2010). Climate change is a classic example that illustrates how phenomena at the international level are rooted in activities and processes at the local level and vice versa. Studying interactions across multiple scales, and the levels on those scales, forms an essential part of what Cash et al. (2006) described as scale dynamics analysis. The body of literature on scale dynamics analysis and its implications for policy making and other forms of governance is growing rapidly (see, for example, Kok and Veldkamp 2011a). However, there is a need for more empirical case study papers to provide experimental insights in the value of the conceptual literature (cf. Kok and Veldkamp 2011b).

One of the discussions in the conceptual literature is whether scales and levels should be seen as "real entities" or as "socially constructed" (Buizer et al. 2011:3,8, Turnhout and BoonmanBerson 2011). The former approach is at the core of many natural science disciplines such as landscape ecology. Within such disciplines, ex ante scale dynamics analysis provides the basis for developing scenarios to inform policy makers about how actions at one scale or level may constrain or provide opportunities at other scales or levels (Cash and Moser 2000).
In the social sciences, both "real" and "constructivist" approaches to scales and levels are used. However, a fundamental difference from its application in the natural sciences is that scale dynamics analysis in the social sciences is mainly used as an analytical tool to reconstruct or evaluate policy processes ex post (see, for example, the work of Bunce et al. 2010, Mandemaker et al. 2011, van der Veen and Tagel 2011, van Lieshout et al. 2011). In line with Manson (2008), we take the position that it is particularly interesting to understand how different applications of scale concepts in research can contribute to more scale-sensitive policy development. Although many scholars have stressed the need for this type of research (cf. Giller et al. 2008, McNie 2007, Termeer et al. 2010, Veldkamp et al. 2011), few case studies exist that explore the potential of ex ante (and ex durante) scale dynamics analysis as part of an action-oriented, social science research approach.

\section{SCALES, LEVELS, AND SCALE DYNAMICS}

In line with the definition used by Gibson et al. (2000:218), we understand scales as: "The spatial, temporal, quantitative, or analytical dimensions used to measure and study any phenomenon." We define levels in line with Termeer et al. (2010:1), who describes levels as: "[T] he units of analysis that are located at different positions on a scale." To illustrate, the spatial scale is an example of a scale, whereas local, subnational, national, regional, and global are the units of analysis or levels on the spatial scale. The literature provides 
Fig. 1. Examples of scales and levels.
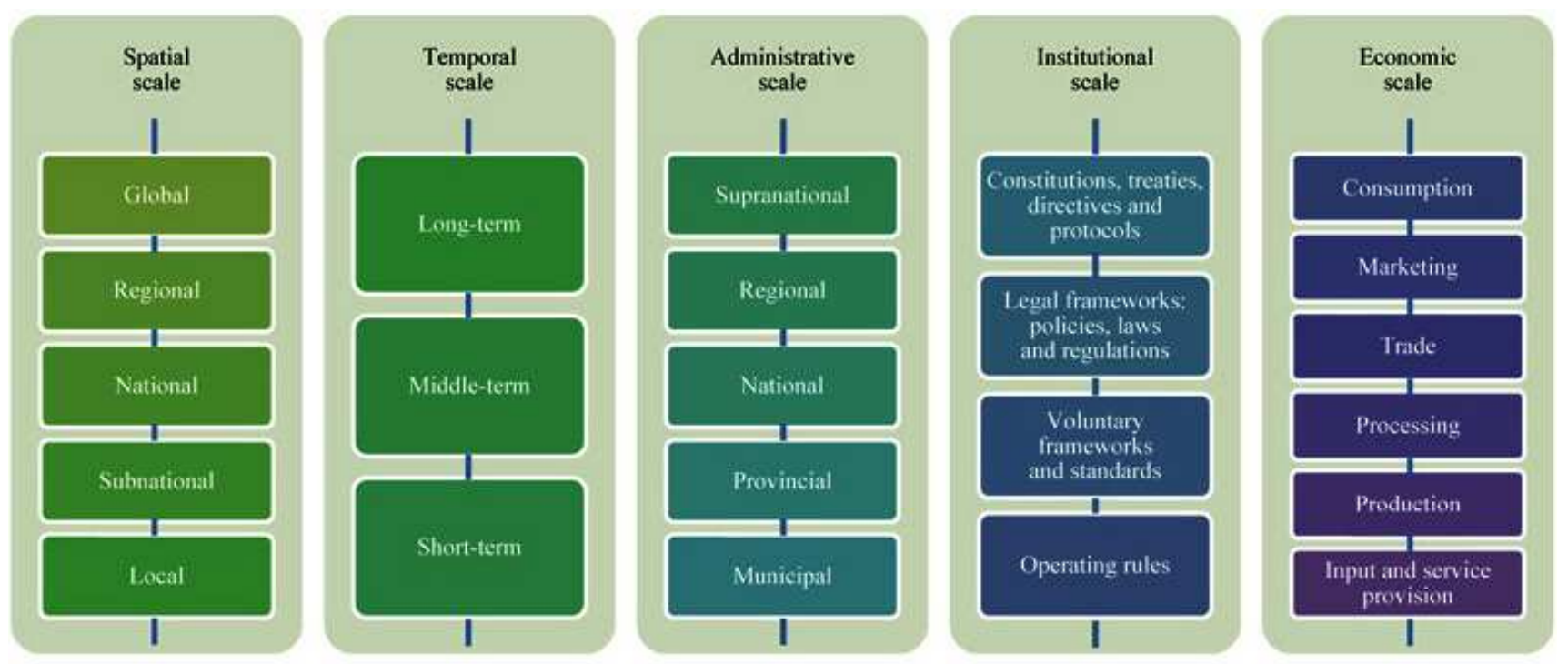

Note: This figure is based on Gibbons et al. 1994, Cash and Moser 2000, Gibson et al. 2000, Cash et al. 2006, Termeer et al. 2010, and Veldkamp et al. 2011.

a wide variety of examples of scales and levels (see Fig. 1). The spatial and temporal scales are among the classics (Termeer et al. 2010), but scales can also be administrative, institutional, or economic. As indicated above, spatial scales include levels relating to geographic space that form the basis for disciplines such as geography and ecology. Temporal scales can be divided in perceptions of time, for example, short-term, middle-term or long-term, or slow and fast (Cash et al. 2006). The administrative or policy scale contains levels of decision making that can range from the supranational level to, for example, the village level. The levels on the administrative scale are closely related to those on the institutional scale that represents different types of regulatory mechanisms that define the "rules of the game." Levels on the institutional scale can range from conventions and treaties to laws and regulations that provide the space within which voluntary frameworks and standards, and operating rules can be established and implemented (Cash et al. 2006). The economic scale expresses the relation between different economic or value-adding activities. The economic scale can be organized as a value chain, with levels ranging from input and service provision, production, processing, trade and marketing, and eventually, consumption. Note that the economic scale can also include other levels (for example, retailers or distributors). Given the scope of our work, we chose to conceptualize the economic scale as the value chain that is visualized in Fig. 1. The choice of levels and their directionality and hierarchy within scales is not always clean- cut and straightforward. For example, within the economic scale, producers and traders can simultaneously be consumers (for example, of food), making their categorization complex.

Cash et al. (2006:2) describe cross-scale dynamics as: "[I] nteractions across different scales", for example, between levels of the spatial and temporal scales. They define crosslevel dynamics as: "[I]nteractions among levels within a scale [...]"; such as between the producers and consumers on the economic scale. In a similar fashion, Cash et al. (2006:2-4, emphasis changed) clarify that: "'Multi-level' is used to indicate the presence of more than one level, and 'multi-scale' the presence of more than one scale, but without implying that there are important cross-level or cross-scale interactions."

Scale dynamics should be interpreted as cross-scale, crosslevel, multi-scale, or multi-level interactions through time, and the various combinations among them (for example, multiscale and cross-level). Accordingly, scale dynamics analysis refers to the process of describing and explaining such interactions.

\section{SCALE DYNAMICS ANALYSIS AND SOLUTION SPACE IN POLICY PROCESSES}

Solution space in policy processes is determined by complex interactions between, for example, spatial, administrative, temporal, economic, and political scales, and the levels on those scales. Such dynamics influence the course and outcome of policy processes. According to Giller et al. (2008), feasible 
policy solutions may emerge from balancing interests and bridging perceptions across different scales and levels. Ex ante scale dynamics analysis can contribute to describing and analyzing interactions between scales and levels and, in so doing, shape the space within which scale-sensitive policy solutions can be explored, designed, and implemented.

Cash et al. (2006) have identified three categories of challenges related to interactions between scales and levels that can affect solution space in policy processes. The first challenge is that of "ignorance," referring to the: "[U]nknown cross-level and cross-scale interactions that take place" (Veldkamp et al. 2011:3), often resulting from a lack of scale or level sensitivity, and resulting in unforeseen or unintended policy responses (cf. Buizer et al. 2011). The second challenge is that of different types of "mismatches" between scales and levels. Mismatches may occur when different scales or levels do not correspond; for example, when seeking to address a transborder or international problem at the national administrative or policy level (Cumming et al. 2006, Veldkamp et al. 2011). Mismatches can also be temporal, where slow institutional procedures are unable to respond to urgent policy issues (Cumming et al. 2006, Termeer et al. 2010). Functional mismatches refer to, for example, unintended negative impacts of new institutional arrangements for stakeholders at a certain level (Cash et al. 2006, McNie 2007). The third challenge, "plurality," refers to the representation and participation of stakeholders and their scale- and level-related interests in policy processes (Cash et al. 2006).

\section{POLICY DEBATE ON SUSTAINABLE BIOFUELS IN MOZAMBIQUE}

In December 2007, the Mozambican government organized a workshop to discuss the proposed European Union (EU) Directive 2009/28/EC (European Union 2009). The Directive includes the EU's criteria for sustainable biofuels and endorses a mandatory $10 \%$ minimum target to be achieved by all member states for the share of renewable energy (including biofuels) in transport-related petrol and diesel consumption by 2020 . At the workshop, it was concluded that the EU had not framed its biofuel policy in light of its development agenda for Africa. Criteria on GHG emissions and indirect land-use change were perceived as being "too ambitious," and it was suggested that they could "scare away potential investors" (Schut et al. 2010a:18). During the workshop, it was decided that a national policy framework for sustainable biofuels should be developed. As part of implementing the country's National Biofuel Policy and Strategy (Resolution 22/2009), the Mozambican government established several interministerial working groups, overseen by a National Biofuel Taskforce. The working group on sustainable biofuels was given the responsibility to: (1) analyze the development of sustainability criteria by different platforms and markets, and develop capacity so that Mozambique could influence the international debate and cooperate with countries in similar positions; (2) develop a national system for sustainable biofuel production that reflects the Mozambican reality and long-term requirements of the major markets; (3) develop criteria for selecting biofuel investment projects; and (4) propose modifications to Mozambique's legal framework to promote a sustainable biofuel sector.

Between December 2008 and November 2010, the lead author of this paper conducted action-oriented research in Mozambique. During this period, the author formed part of a Technical Secretariat, responsible for conducting research to support the working group for sustainable biofuels in achieving its objectives.

\section{RESEARCH OBJECTIVE AND APPROACH}

Our objective is to explore how different types of scale dynamics analysis can contribute to a better understanding of the interactions between scales and levels, and how they influence solution space in policy processes. We also reflect on the opportunities and challenges related to conducting ex ante scale dynamics analysis as part of an action-oriented, social science research approach.

Upon arrival in Mozambique in December 2008, we developed our research approach in collaboration with the Mozambican government. One of the first challenges was defining the system's boundaries and making choices about what scales and levels to include and exclude in the research. Based on the objectives of the working group as formulated in Mozambique's National Biofuel Policy and Strategy, a research approach for scale dynamics analysis unfolded. The scale dynamics analysis contained two phases (Fig. 2). Within both phases, the main focus was on analyzing interactions between administrative, institutional, and economic scales and levels. Occasionally, we also referred to the influence of interactions with other scales and levels. Based on the changing policy context and progressive insights resulting from the research, we continuously monitored and evaluated the system's boundaries and whether new scales or levels had to be included in the analysis.

Phase I contained the actual ex ante analysis of scale dynamics in the policy debate on sustainable biofuels in Mozambique. The first phase contained two steps. Step 1 focused on crossscale and cross-level dynamics within and across the administrative, institutional, and economic scales. It described and analyzed the interactions between different types of biofuel protocols and directives, legal and voluntary frameworks (levels on the institutional scale) developed at supranational, regional, and national policy levels (administrative scale), and analyzed how this influences biofuel trade and market access (economic scale). The objective was to identify matches and mismatches between different scales and levels (Fig. 3). In other words, we analyzed various frameworks for sustainable biofuels developed by 
different administrative bodies, determined how they relate to the biofuel objectives of the Mozambican government, and indicated the implications in terms of the trade and marketing of biofuels produced in Mozambique.

Fig. 2. Research approach.

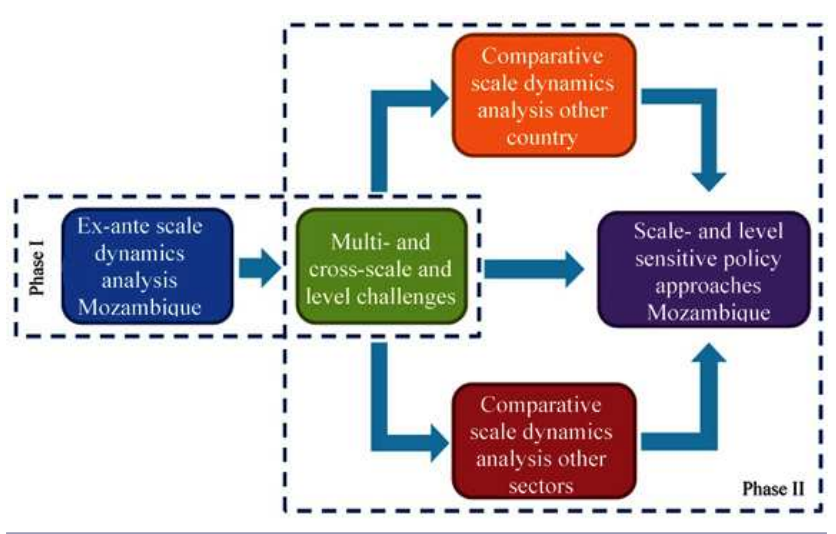

Fig. 3. Schematic representation of scale dynamics analysis: Step 1, Phase I.

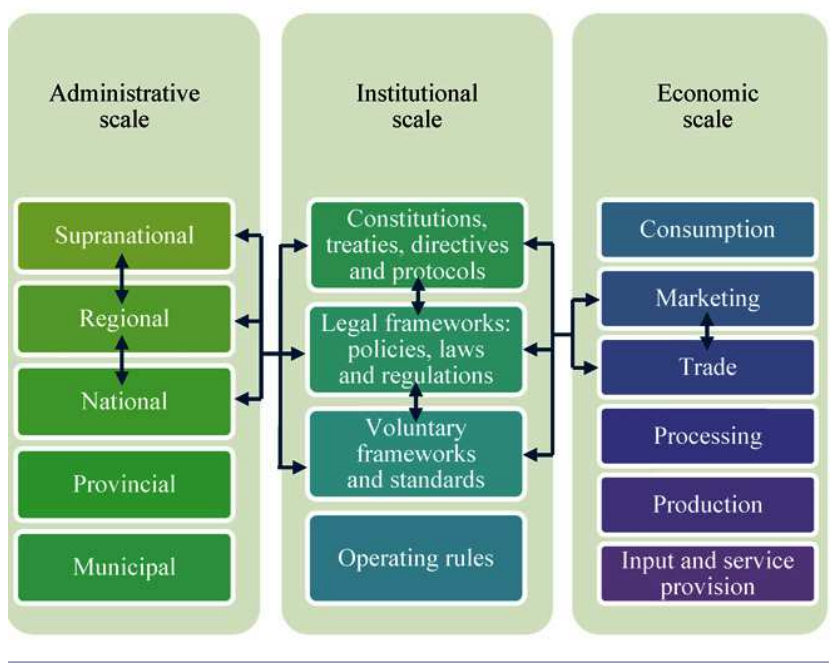

Step 2 in Phase I described and analyzed the relation between the Mozambican government's policy objectives formulated in the country's National Biofuel Policy and Strategy and the practice of biofuel developments in Mozambique. In doing so, we explored cross-scale and cross-level dynamics between levels on the administrative and economic scales. We examined the impact of the Mozambican government's legal framework on operating rules and the practice of biofuel production and processing in Mozambique. We also studied how production and processing is influenced by the availability of input and service provision and trade and market dynamics. As part of this second step, we elaborated on the existing legal frameworks that govern agreements between the Mozambican government and biofuel producers and processers, such as the investment guidelines and the legal process for the acquisition of land (Fig. 4).

Fig. 4. Schematic representation of scale dynamics analysis: Step 2, Phase I.

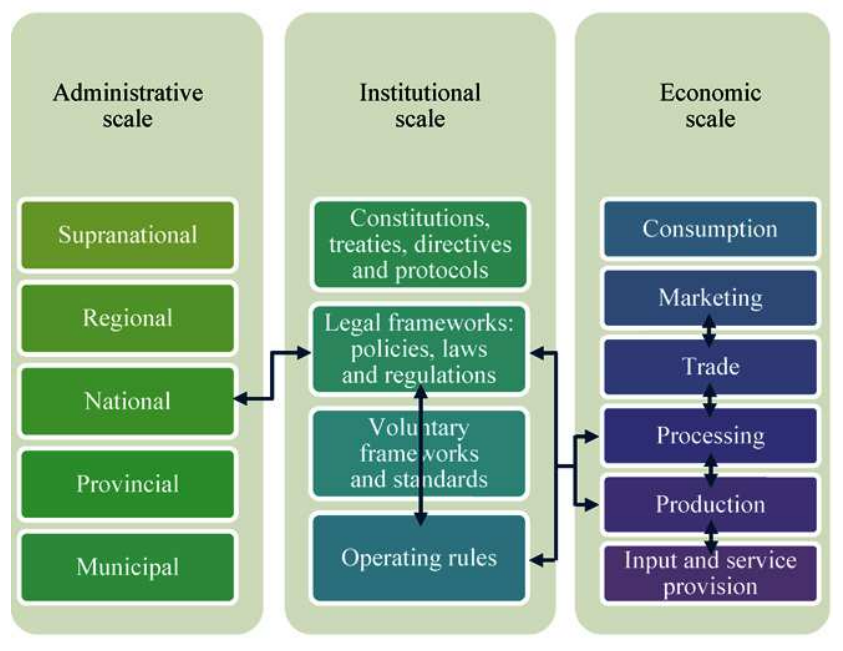

Phase II built on the ex ante scale dynamics analysis of Phase I that revealed a number of mismatches and policy challenges for developing a national institutional framework for sustainable biofuels in Mozambique. Phase II also contained two steps. Because of the relative newness of biofuels in Mozambique (as well as in other subsaharan African countries), we analyzed comparative cross-scale and crosslevel interactions in Brazil, a country with a long history in producing, processing, trading, and using biofuels. Therefore, Step 3 included an analysis of the legal frameworks (institutional scale) developed by the Brazilian government (positioned at a similar level as the Mozambican government on the administrative scale) to promote and regulate the sustainability across different levels of its biofuel value chain (economic scale). In the analysis, the main focus was on the production and processing levels on the economic scale, although developments at the level of input and service provision, trade and marketing of Brazilian biofuels were also analyzed (Fig. 5).

In Step 4, we applied a similar type of scale dynamics analysis as was used in Step 3. To learn more about scale dynamics related to certification and sustainability in Mozambique, we conducted a comparative analysis of scale and level interactions in other sectors in Mozambique that produce commodities under sustainability frameworks and standards. 
We focused on dynamics between levels on the institutional scale (for example, voluntary frameworks and operating rules), that were developed at supranational and national levels (administrative scale) and how they influence production and processing dynamics on the economic scale. As in Step 2 and 3 , we also analyzed dynamics across the levels of input and service provision, trade, and marketing (Fig. 6).

Fig. 5. Schematic representation of scale dynamics analysis: Step 3, Phase II.

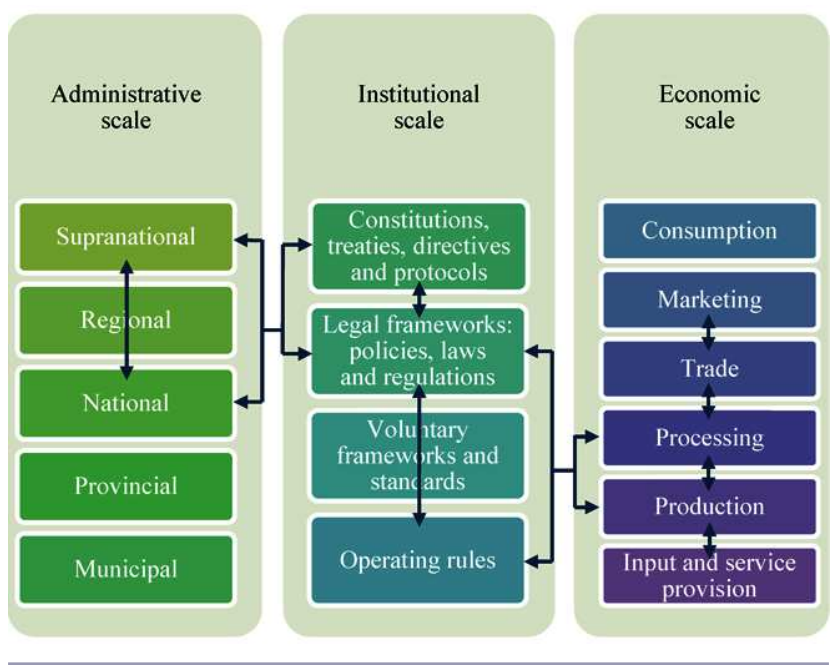

Fig. 6. Schematic representation of scale dynamics analysis: Step 4, Phase II.

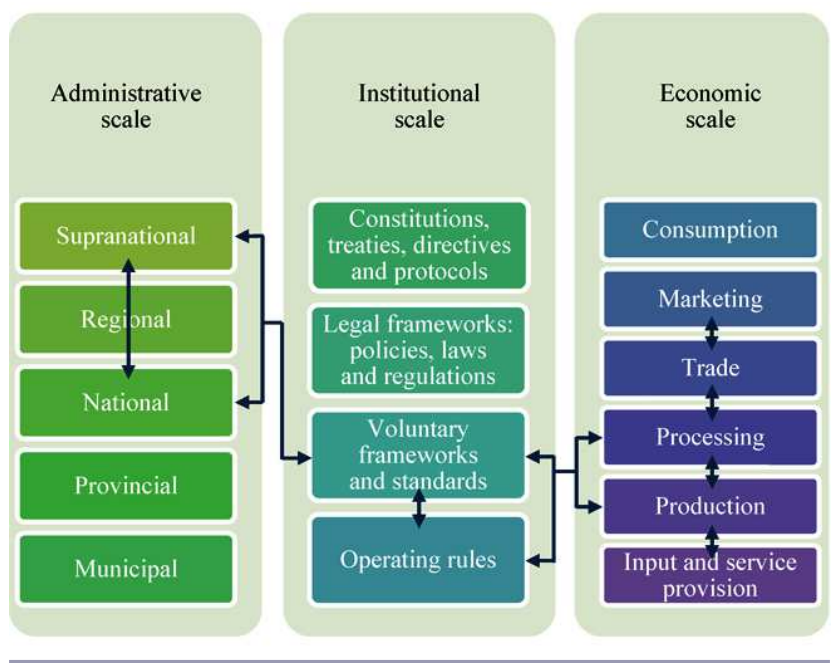

As part of Phase II, we described and analyzed how interactions between administrative, institutional, and economic scales and levels have evolved over time. We also examined how different types of scale- and level-related challenges have been addressed; for example, by the Brazilian government. This, together with findings from Phase I, provided input for developing policy scenarios and recommendations. This supported the Mozambican government's working group in decision making and the achievement of its policy objectives.

\section{PHASE I: EX ANTE SCALE DYNAMICS ANALYSIS}

\section{Step 1: Analyzing (inter)national institutional biofuel frameworks}

In line with the working group's first objective, four-at the time, leading - institutional frameworks for sustainable biofuels were analyzed and compared. These were: (1) the Dutch Cramer Criteria; (2) the UK Renewable Transport Fuels Obligation (RTFO); (3) the EU Directive for Sustainable Biomass Production (Directive 2009/28/EC); and (4) Version $\underline{0 \text { of the Global Principles and Criteria for Sustainable Biofuels }}$ Production, produced by the Roundtable on Sustainable Biofuels (RSB). A summary and comparison of these four frameworks is provided in Appendix 1. The RSB is a voluntary framework; the Dutch, UK, and EU frameworks are directives that promote sustainable biofuel production. For EU member states, only biofuels produced in compliance with the EU's sustainability criteria may count as part of the $10 \%$ minimum target and will be eligible for the market incentives for biofuels sold on the EU market (European Union 2009). The implementability of the criteria developed at the UK and Dutch national administrative levels was, at that time, questionable, as some criteria were potentially in conflict with international legal frameworks. For example, the World Trade Organization's "national treatment principle" requires that products from other countries should be treated the same way as products manufactured in the importing country, and that regulations and standards should not create unnecessary trade obstacles (Bauen et al. 2005, van Dam et al. 2008). However, the categorization of products using GHG emission reduction, biodiversity, or environmental criteria is possible (Woods and Diaz-Chavez 2007). This partly explains the EU's "(narrow) focus on climate and biodiversity" and lack of detailed social and economic criteria in its framework for sustainable biofuels (Di Lucia 2010:7400).

During a later phase in the research, we analyzed frameworks for sustainable biofuels developed by the Better Sugarcane Initiative (BSI, Version 2), Global Bioenergy Partnership (GBEP) and the South African Development Community (SADC) framework for sustainable biofuels. The SADC framework in particular implied the inclusion of an additional (regional) administrative level in the scale dynamics analysis. Subsequently, the National Biofuel Policy and Strategy of Mozambique was analyzed. In this document, the Mozambican government's vision on biofuels is described as to: "Make use of agro-energy resources to diversify the range 
Fig. 7. Project application and land acquisition process (CEPAGRI 2008).

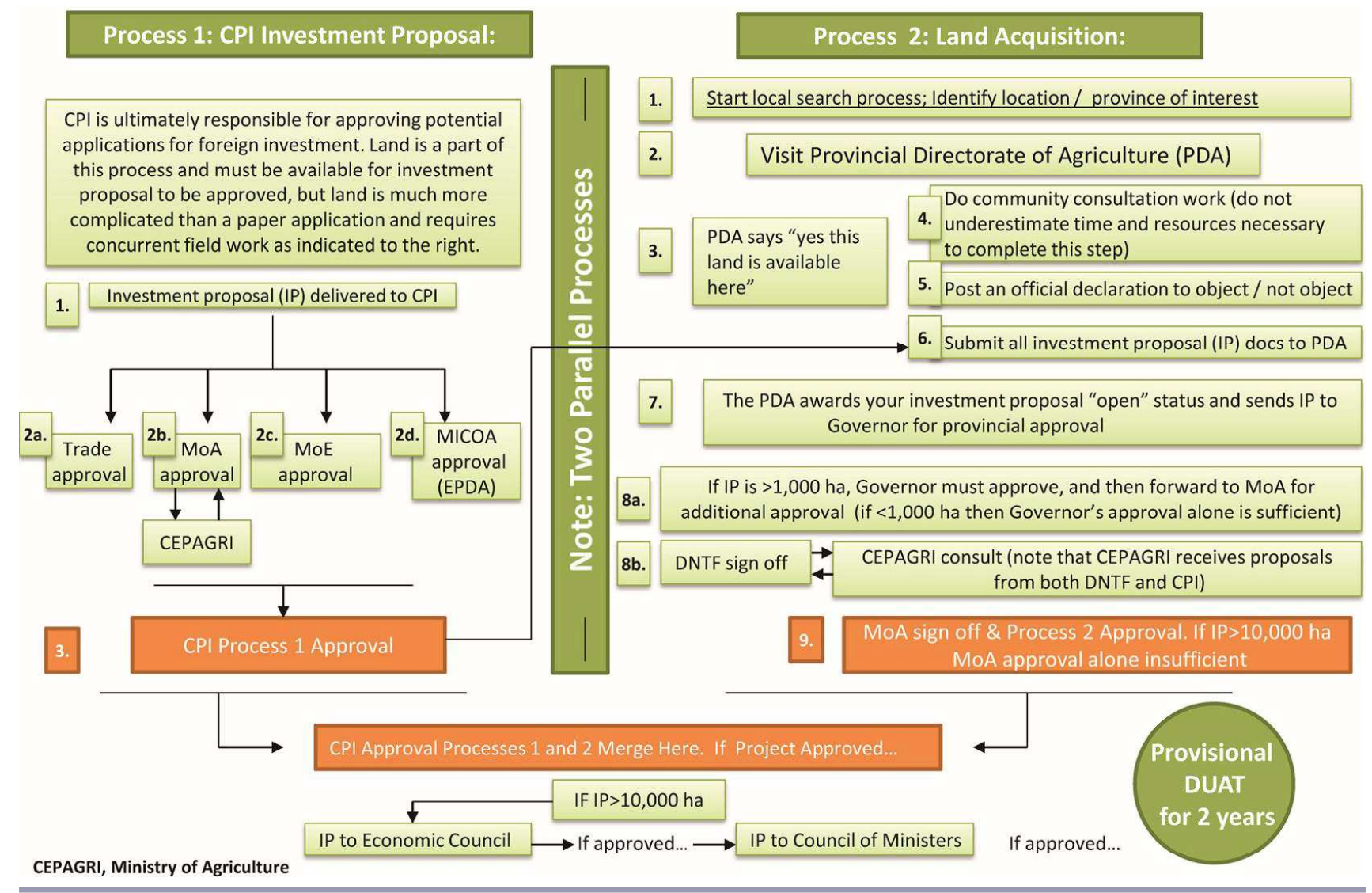

of energy sources, benefit the population and enhance socioeconomic development, especially of the population of rural areas" (Government of Mozambique 2009:11).

Although the Mozambican National Biofuel Policy and Strategy has limited regulatory and legal power, it describes several measures intended to promote biofuel production, while limiting potential negative impacts on society and the environment. Some of the measures are: proposed limits on land allocation based on agro-ecological land zoning; preventing negative impacts on food security; approval of selected feedstock, that is, sugarcane and sweet sorghum for ethanol, and coconut and jatropha for biodiesel; the use of sustainability criteria to select investment projects and allocate land titles; the creation of a domestic market for biofuels through blending mandates; increasing exports to create tax revenues and foreign currency; and the promotion of regional markets for biofuels. We concluded that the objectives of the Mozambican government generally correspond with the sustainability principles of the SADC framework; notably those on energy security, economic development, and food security. This can be explained by the fact that the
Mozambican and SADC frameworks were developed parallel to each other and in an integrated way. Moreover, aligning with the SADC principles for sustainable biofuels would facilitate access to the regional SADC market, one of the objectives of the Mozambican government. Analysis of other existing biofuel-related institutional frameworks in Mozambique revealed that data requirements under the existing Project Application and Land Acquisition Processgoverned by the Mozambican investment law and land law, and their regulatory frameworks (Fig. 7) — could potentially be adapted to assess the sustainability of biofuel operations in Mozambique. An assessment of the performance of companies after two years provides the Mozambican government with a legal instrument to invalidate the land titles of companies that do not comply with Mozambican legislation. This occurred in December 2009, when the government voided the contract of a large sugarcane-for-bioethanol project, as the company failed to comply with their contractual obligations (Schut et al. 2010b).

Next, (trade) agreements and treaties between Mozambique and other national and supranational administrations were 
analyzed. Duty-free access for ethanol, biodiesel, and vegetable oil exports from Mozambique to the EU is granted under two key agreements: (1) the Cotonou Protocol between the EU and African, Caribbean, and Pacific countries, which is in the process of being transformed into a regional economic partnership agreement (EPA) between the EU and SADC, and (2) the Everything But Arms arrangement, which grants dutyfree access to the EU market for all goods (except arms) for least-developed countries. The SADC Trade Protocol provides duty-free access for Mozambican products to 10 other SADC countries (Botswana, Lesotho, Malawi, Mauritius, Namibia, South Africa, Swaziland, Tanzania, Zambia, and Zimbabwe) and is aimed at promoting regional trade (Schut et al. 2010b). In terms of promoting the sustainability of the emerging biofuel sector in the country, Mozambique is signatory to international treaties on sustainability, such as the Kyoto Protocol, and experiences a degree of political pressure to demonstrate: "[G]oodwill to international donors and powerful trade partners in consideration of the large share of donations contributing to the national budget" (Di Lucia 2010:7401).

\section{Step 2: The practice of biofuel production and processing in Mozambique}

To better understand the practice of biofuel production and processing in Mozambique, we analyzed 10 existing biofuel projects and interviewed close to 50 stakeholders, including policy makers and representatives of the private sector and civil society organizations. The analysis showed the diversity among biofuel producers and processors, and that promoting sustainable smallholder biofuel production requires a different set of policy measures than those needed to sustainably develop the commercial sector (Schut et al. 2011b). Furthermore, the analysis enabled us to identify different stakeholder groups at different levels; their objectives in relation to biofuel sustainability; their preferences with regard to the institutional embedding of a national framework for sustainable biofuels; and ideas about how the policy process of developing such a framework should be organized. Civil society stakeholders in particular complained about the limited participation and collaboration with the government working group.

The above data were complemented by an analysis of biofuel investment proposals. This demonstrated how the lack of operating rules was creating a gap between the biofuel policy objectives of the Mozambican government and the practice of biofuel developments in Mozambique. For example, the majority of commercial biofuel producers and processors showed no interest in establishing themselves in remote rural areas, nor did they focus on areas identified under the agroecological land zoning. In contrast, these producers and processors preferred to locate themselves in areas where they have access to input and service providers, and close to deepsea harbors to export their produce to overseas markets such as the EU. Another mismatch was that employment creation as estimated by investors was much lower than expected by the government (Schut et al. 2010b). As our study unfolded, the climate on the global financial markets worsened. Several biofuel operators in Mozambique faced bankruptcy, and several projects were abandoned by investors, leaving behind deforested areas and unemployed workers. This created awareness about the necessity to have strict criteria to regulate the financial sustainability of the biofuel sector and that, in relation to Step 1, such criteria were largely absent within the existing institutional frameworks. It also shows the need for flexibility and adaptive capacity to adjust institutional frameworks according to the changing dynamics along the economic scale.

\section{PHASE II: COMPARATIVE SCALE DYNAMICS ANALYSIS}

Some challenges and potential mismatches that emerged from the ex ante analysis of scale dynamics analysis in Phase I provided input for Phase II. The following questions arose: What are the advantages and disadvantages of different types of institutional frameworks to regulate sustainable biofuels? How can a framework for sustainable biofuels address the diversity of commercial and smallholder biofuel producers and processors? How can flexibility and adaptive capacity be created in developing and implementing the institutional framework? How can a framework for sustainable biofuels be developed that can bring together, rather than divide, different stakeholder groups? We explored possible answers to these questions by analyzing comparable scale dynamics in Brazil and in other Mozambican sectors where commodities are produced under sustainability or certification schemes.

\section{Step 3: Learning from a scale dynamics analysis of Brazil}

A desk study was conducted to analyze how some of the abovementioned challenges had been addressed by the Brazilian government. The rapid expansion of the biofuel sector in Brazil and its negative impact on biodiversity have resulted in criticism from the EU, with proposals to restrict market access for unsustainably produced biofuels from Brazil (Keeney and Nanninga 2008). As a response to international political pressure, Brazil developed several institutional mechanisms that regulate the sustainability in the biofuel sector, including providing incentives to stimulate partnerships between commercial and smallholder producers, improving the financial sustainability of the sector, and promoting investments in research and development to continuously improve the productivity, efficiency, and overall sustainability of the biofuel sector. Many of these issues are similar to current and potential future challenges faced by the Mozambican government.

With regard to the institutional scale, the analysis showed that no additional sustainability framework or certification 
schemes are necessary if a country's existing legal framework regulates the (negative) impacts of activities along various levels of the economic scale; especially with regard to biofuel production and processing. Such an institutional approach to regulating sustainable biofuels is in line with the objectives of the Mozambican government's working group, and could reduce the additional bureaucratic and financial burden for both the government and biofuel investors. It must be said that law enforcement in Brazil is generally weak, and consequently many biofuel producers and processors still fail to comply with existing legislation (for example, Smeets et al. 2008).

The analysis of dynamics between administrative, institutional, and economic scales in Brazil over time demonstrated the need for adaptive capacity in developing and implementing an institutional framework for sustainable biofuels. The following example will illustrate this. During the early 1990s, the Brazilian government started promoting mechanized sugarcane harvesting to decrease GHG emissions and other types of air pollution that were resulting from cane burning, a process necessary to facilitate manual harvesting (van Dam et al. 2008). Cane burning is also regarded as unsustainable because it damages the ecosystem and soil structure, and it is hazardous to the health of cane cutters. However, as a result of the introduction of mechanized harvesting, employment in the Brazilian sugarcane sector dropped by almost 50\% between 1992 and 2003, causing social and economic problems for cane cutters and their families (Schut et al. 2010a). This example shows how definitions of sustainable biofuels at certain administrative levels may change over time, and that the institutional frameworks and the administrative bodies that develop them should be responsive to such change.

\section{Step 4: Learning from scale dynamics analysis in other Mozambican sectors}

To learn more about the institutional dynamics in Mozambique, we analyzed the production of commodities in Mozambique under voluntary certification schemes or sustainability criteria such as the Forest Stewardship Council (FSC), GLOBALG.A.P., and Fairtrade International, which were all developed at the supranational administrative level (Appendix 2 provides a brief overview of each of these). Data were collected by analyzing secondary data, doing interviews, and conducting field visits to companies and projects.

The analysis of GLOBALG.A.P. demonstrated that mainstream certification can easily result in the exclusion of smallholder producers from markets. This is because few small producers have the human or financial resources to comply with sustainability or certification schemes. Thus, the need for capacity building, alternative procedures, and group certification for smallholders is crucial. Within the commercial sector, it is also important to address the heterogeneity of biofuel producers. Both FSC and Fairtrade have developed gradual systems that seek to respect producers in their local context. The Forest Stewardship Council, for example, allows starting companies to comply with basic standards, whereas more "mature" companies are subject to higher standards and stricter audits. Nevertheless, the vast majority of Mozambican timber is produced unsustainably and extracted illegally, mainly because of the lack of enforcement of laws, regulations, and standards; this is a major challenge in Mozambique (World Bank 2009).

Only a very small segment of the Mozambican national market is supplied by commodities produced under voluntary sustainability frameworks. Production under voluntary standards is mainly for overseas markets, as the higher production costs relating to certification do not allow for competition on the domestic market. Moreover, there are few companies that perform audits, and there is a general lack of facilities (such as laboratories) that can provide standardization or certification services. In response to the lack of contextualization and national support for FSC certification, a number of national Mozambican public and private stakeholders founded the Association for Responsible Forestry (AGREF) in December 2010. AGREF's main objective is to establish an FSC National Office and to develop a national standard for FSC forest certification in Mozambique that will make it easier and cheaper to become FSC certified. It shows how new multi-stakeholder administrative bodies at the national level may be needed to facilitate the development of a feasible, acceptable, and affordable institutional framework, and - eventually — to enforce the adequate monitoring of that framework.

\section{SCALE DYNAMICS ANALYSES AND SOLUTION SPACE IN THE POLICY DEBATE ON SUSTAINABLE BIOFUELS IN MOZAMBIQUE}

Phases I and II together contributed to a better understanding of a variety of scale- and level-related dynamics in which the policy debate on sustainable biofuels in Mozambique is embedded. The ex ante analysis of scale dynamics identified different types of challenges related to interactions between administrative, institutional, and economic scales and levels. Together with findings from the comparative scale dynamics analysis, strategies for dealing with these challenges were identified. Below, we analyze how this shaped solution space in the policy debate on sustainable biofuels in Mozambique.

\section{Reduce ignorance and create awareness of interactions between scales and levels}

The Mozambican government's feedback on EU Directive $2009 / 28 /$ EC and the objectives of the working group; that is, to influence the international debate on biofuels and develop a framework that reflect requirements of major biofuel markets; demonstrate some degree of awareness about crossscale and cross-level administrative, institutional, and economic dynamics on the part of the Mozambican 
government. However, there was very little information about how these interactions would affect the unfolding biofuel sector in Mozambique and how it would influence the administrative and institutional space within which a national framework for sustainable biofuels could be developed. Therefore, a fundamental first step was to describe and analyze existing institutional frameworks developed at different administrative levels, and explore the opportunities and challenges this provides in terms of the production, processing, trade, and marketing of biofuels (levels on the economic scale) for Mozambique.

This also demonstrated how institutional frameworks for sustainable biofuels are shaped by multiple objectives, priorities, and trade-offs at different administrative levels and spatial levels. The EU sustainability criteria for biofuels are not the same as the Dutch criteria, and the Dutch framework is not the same as the UK framework, although they were developed at the same level on the administrative scale. The alignment of institutional frameworks can have economic and political consequences in terms of trade, market access, or demonstrating political goodwill.

The analysis of interactions between the levels on the administrative, institutional, and economic scales in Mozambique raised awareness about the diversity of biofuel activities along the economic scale, and about how the biofuel practice related to the biofuel policy objectives formulated in the National Biofuel Policy and Strategy of the Mozambican government. It demonstrated the need for the timely development of an institutional framework to align economic activities (especially biofuel production and processing) with the policy objectives of the Mozambican government. In addition, it triggered thinking about what type of institutional framework could harmonize the objectives that play at different levels on the administrative (national government) and economic scales (producers and processors).

An underlying question exposed by the analysis was how an institutional framework could address the diversity existing at the production level of the economic scale. In other words, how it could differentiate between commercial and smallholder biofuel producers. The analysis of such dynamics in other sectors showed how certification and sustainability schemes can easily result in obstacles for smallholder producers to access markets, but also how schemes such as FSC responded to such challenges by developing alternative and gradual procedures and operating rules.

In terms of the working group's objectives, the analysis shaped the solution space for exploring a national institutional framework for sustainable biofuels that could reflect: (1) the long-term requirements of different regional and international markets and, by doing so, facilitate the trade and marketing of biofuels produced in Mozambique and demonstrate political goodwill; and (2) the Mozambican reality, by developing a more realistic idea about Mozambique's emerging biofuel economy and how it relates to, and is influenced by, legal frameworks developed at the national administrative level.

\section{Scale and level matches and mismatches and adaptive capacity in policy development}

The ex ante analysis of dynamics between the administrative, institutional, and economic scales and levels revealed existing and potential mismatches, but also matches. Mismatches resulted primarily between levels on the administrative and institutional scales, resulting from different perceptions on sustainable biofuels and the type of institutional frameworks necessary to promote a sustainable biofuel sector. More specifically, the focus on climate and biodiversity in the institutional framework developed by the EU did not reflect the socioeconomic and energy security policy objectives developed at the Mozambican national level.

Another mismatch occurred because of the absence of an adequate institutional framework to guide biofuel activities at the economic scale in Mozambique. This resulted in operating rules and biofuel activities that did not reflect the Mozambican government's objectives; for example, promoting biofuel production in remote rural areas. Insights into potential mismatches to which an institutional framework for sustainable biofuels could be exposed emerged mainly from the comparative analysis of scale and level interactions in Brazil (Step 3) and in other Mozambican sectors (Step 4). Mismatches emerged particularly at the interface of the institutional scale and the economic scale. A good example is the general lack of law enforcement whereby both Brazil's and Mozambique's legal institutional frameworks are not translated into operating rules. Consequently, the institutional frameworks have only limited regulatory influence on activities along the economic scale, such as the production and processing of biofuels or other commodities.

Matches across scales and levels were also identified. For example, integrating the criteria for sustainable biofuels into the existing institutional legal framework governing the Project Application and Land Acquisition Process could create win-win situations for investors and the Mozambican government, without negatively affecting the production of biofuels by smallholders. Furthermore, the analysis demonstrated the economic advantages of collaborating with other countries at the regional level, as SADC member states adopted regional principles for sustainable biofuels that could facilitate duty-free access for Mozambican biofuels to the majority of other SADC countries under the SADC Trade Protocol. Aligning with the SADC framework was also politically desirable, as it could: (1) increase the legitimacy of the institutional framework for sustainable biofuels developed by the Mozambican government, (2) strengthen the political position of Mozambique in the international debate on sustainable biofuels, and (3) facilitate cooperation with 
countries in similar positions. These were all key objectives of the Mozambican government's working group.

Definitions of sustainable biofuels are prone to change over time, and mismatches will need to be addressed continuously. This is illustrated by the increasing attention placed on financial and economic sustainability in the institutional frameworks for sustainable biofuels that were developed during the global financial and economic crisis. The analysis of scale dynamics in the Brazilian biofuel sector also demonstrated how institutional frameworks developed at the national administrative level evolve over time. They can change as a result of changes at other institutional levels, for example, new international treaties or protocols; changing market demands, for example, for sustainable biofuels; or the availability of new production technologies, for example, mechanized harvesting. To deal with such dynamics, adaptive capacity in developing and implementing institutional frameworks is crucial, but also very challenging (cf. Gunderson and Holling 2002, Cumming et al. 2006, Olsson et al. 2007, Allen and Holling 2010, Termeer et al. 2010).

\section{Plurality and collaborative stakeholder learning}

Scale dynamics analysis contributed to identifying key stakeholders. These included representatives of supranational bodies, national governments, civil society organizations, commercial and smallholder producers, and others. Consequently, it provided insights into stakeholder objectives and mutual (power) relationships; for example between the EU and the Mozambican government. It captured not only stakeholder perceptions concerning what type of institutional framework would be most effective for the Mozambican context and what principles and criteria for sustainable biofuels should be included in the framework, but also expectations about how the policy process should be organized, and stakeholders' perceived roles, rights, and responsibilities in that process (Schut et al. 2013). As there had been limited space for multi-stakeholder debate on sustainable biofuels in Mozambique, it highlighted the need for the Mozambican government's working group to intensify collaboration with different stakeholder groups operating across the different administrative, institutional, and economic scales and levels. According to Bunce et al. (2010), this can make policy more responsive to the needs of different stakeholders.

The comparative analyses during Phase II provided a number of examples of how cross-scale and cross-level multistakeholder collaboration could be organized to develop a sustainability framework that reflects the key interests of different stakeholder groups. Moreover, the analyses created awareness that multiple institutional approaches may be needed to address plurality across and within levels of the economic scale, for example, commercial and smallholder producers and processors, and to respect the plurality of stakeholders, their objectives, and needs at different levels.

\section{SCALE DYNAMICS ANALYSIS IN ACTION- ORIENTED RESEARCH: OPPORTUNITIES AND CHALLENGES}

Based on our experiences and contribution to the policy debate on sustainable biofuels in Mozambique, we conclude that ex ante scale dynamics analysis can make an important contribution to more scale-sensitive policy development. It allows for challenges related to scale and level interactions (as well as potential solutions) to be identified and addressed at an early stage in the policy process. The comparative analyses of interactions between scales and levels in other countries and other sectors provided valuable insights that broadened the space within which policy options to regulate the sustainable production of biofuels in Mozambique could be explored. The analyses emphasized the need for multistakeholder collaboration, adaptive capacity in the policy process, and the advantages and disadvantages of different types of institutional frameworks, which we, as Technical Secretariat, proposed to the Mozambican government's working group.

We want to provide the reader with an idea of what this contributed to. The research findings that resulted from the ex ante scale dynamics analysis provided the basis for drafting principles and criteria for the sustainable production of biofuels in Mozambique, and for developing a guide for policy implementation. This was executed by the interministerial working group which was supported by the Technical Secretariat. The proposed policy framework was discussed during three stakeholder consultation workshops that were organized in May and October 2010 in different parts of the country. Over 150 representatives of the donor community, Mozambican government, private sector, NGOs, and civilsociety organizations participated in the workshops. During the workshops, stakeholders negotiated about the formulation of the sustainability principles and criteria, and discussed the proposal to integrate the framework with the government's existing Project Application and Land Acquisition Process. Between July 2011 and June 2012, the framework was further operationalized and sustainability indicators and verifiers were developed. Again, three stakeholder consultation workshops were organized in different parts of the country. In June 2012, an operationalized version of the framework was finalized and presented to stakeholders, making Mozambique the first African country to develop a national policy framework for sustainable biofuels. At the time this paper was published, the framework was prepared for approval by the Mozambican Council of Ministers. The policy process in Mozambique has attracted considerable attention, both within the SADC region as well as in the EU. As part of a broader set of legal instruments and incentives, the sustainability framework will further enable the Mozambican government to regulate economic biofuel activities in the country. A first impact is that as a result of recently approved biofuel blending targets, more biofuel producers and processors are expressing 
interest in trading their produce on the Mozambican market, instead of exporting biofuels to the EU.

There are a number of methodological and analytical challenges related to conducting ex ante scale dynamics analysis as part of an action-oriented, social science research approach. The action-oriented research approach enabled us to include or exclude scales and levels from the analysis and to redefine the system's boundaries as the research and policy debate unfolded. This shaped the research dynamic and made it possible to respond to the changing policy context and, consequently, to enhance the practical relevance of the ex ante scale dynamics analysis in support of the policy process. However, it also posed challenges. Choices about what scales and levels to include and exclude in the analysis could not easily be made in collaboration with the different stakeholder groups operating across different scales and levels. They were often based on choices made by the researcher, which can be questioned given that decisions about what scales and levels to include or exclude influence the type of scale awareness that the research creates, the matches and mismatches that are identified, and the perceived appropriateness of different stakeholders to participate in the policy process. Here, we touch upon more deeply-rooted discussions about the roles for researchers in policy processes (Schut et al. 2011a) and the division of tasks and responsibilities between research and stakeholders in policy processes (for example, Jasanoff 1990, Hoppe 2005, Schut et al. 2013). In line with Kok and Veldkamp $(2011 b)$, we conclude that on processes of scale and level inclusion and exclusion, as well as on other (practical) applications of scale concepts, further empirical research is urgently needed.

\section{CONCLUSIONS}

We have explored how ex ante scale dynamics analysis as part of an action-oriented social science research approach can contribute to a better understanding of interactions between scales and levels and how they influence solution space in policy processes. Based on our findings, we conclude that ex ante scale dynamics analysis can effectively contribute to transforming challenges resulting from interactions between different scales and levels into opportunities by: (1) creating awareness about these interactions between scales and levels, and their implications for policy, (2) identifying scale and level matches and mismatches and develop adaptive capacity to deal with them, and (3) identifying key stakeholder groups and their scale- and level-related interests that can provide the basis for collaborative stakeholder learning. In so doing, ex ante scale dynamics analysis can contribute to more scale-sensitive policy development.

Processes of scale and level inclusion and exclusion form an essential part of scale dynamics analysis in action-oriented research. On the one hand, it keeps the research flexible and enables the researcher to respond to the changing policy context and stakeholder needs. On the other hand, such choices influence the type of awareness the research creates, the type of matches and mismatches that are identified, and the perceived appropriateness of stakeholder groups to participate in exploring and designing policy solutions. How to legitimize such choices in an action research setting is complex and requires further empirical study.

Responses to this article can be read online at: http://www.ecologyandsociety.org/issues/responses. $\mathrm{php} / 5310$

\section{Acknowledgments:}

This study contributed to the strategic research programme 'Sustainable spatial development of ecosystems, landscapes, seas and regions, 'funded by the Dutch Ministry of Economic Affairs. The research also formed part of the 'Competing Claims-Competing Models' programme jointly funded by Wageningen University and Research Centre and the Dutch Ministry of Foreign Affairs. The authors acknowledge the valuable contributions of colleagues, especially Kasper Kok, and the journal's reviewers who provided constructive and very accurate feedback that substantially improved the quality of this paper. Special thanks to all investors, farmers, extension workers, researchers, $N G O$ representatives and policy makers from Mozambique who collaborated with us and provided data and insights necessary for this study.

\section{LITERATURE CITED}

Allen, C. R., and C. S. Holling. 2010. Novelty, adaptive capacity, and resilience. Ecology and Society 15(3): 15. [online] URL: http://www.ecologyandsociety.org/vol15/ iss 13/art24/

Bauen, A., J. Howes, A. Chase, R. Tipper, A. Inkinen, J. Lovell, and J. Woods. 2005. Feasibility study on certification or a Renewable Transport Fuel Obligation (RTFO). E4tech, ECCM and Imperial College London, London, UK.

Buizer, M., B. Arts, and K. Kok. 2011. Governance, scale, and the environment: the importance of recognizing knowledge claims in transdisciplinary arenas. Ecology and Society 16(1): 21. [online] URL: http://www.ecologyandsociety.org/vol16/ iss $21 / \operatorname{art} 21 /$

Bunce, M., K. Brown, and S. Rosendo. 2010. Policy misfits, climate change and cross-scale vulnerability in coastal Africa: how development projects undermine resilience. Environmental Science and Policy 13(6):485-497. http://dx.doi.org/10.1016/ j.envsci.2010.06.003 
Cash, D. W., and S. C. Moser. 2000. Linking global and local scales: designing dynamic assessment and management processes. Global Environmental Change 10(2): 109-120. http://dx.doi.org/10.1016/S0959-3780(00)00017-0

Cash, D. W., W. N. Adger, F. Berkes, P. Garden, L. Lebel, P. Olsson, L. Pritchard, and O. Young. 2006. Scale and crossscale dynamics: governance and information in a multilevel world. Ecology and Society 11(2): 8. [online] URL: http:// www.ecologyandsociety.org/vol11/iss12/art18/

CEPAGRI. 2008. Project application and land acquisition process. Mozambican Ministry of Agriculture, Maputo, Mozambique. [online] URL: http://siteresources.worldbank. org/EXTARD/Resources/336681-1236436879081/5893311-1271205116054/AlbinoPresentation.pdf

Coulibaly, A. L., and P. Liu. 2006. Regulations, standards and certification for agricultural exports: a practical manual for producers and exporters in East Africa. Food and Agriculture Organization (FAO), Rome, Italy. [online] URL: http://www. fao.org/docrep/010/a0791e/a0791e00.HTM

Council of the European Union. 2008. Proposal for a Directive of the European Parliament and of the Council on the promotion of the use of energy from renewable sources (17086/08). Brussels, Belgium.

Cumming, G. S., D. H. M. Cumming, and C. L. Redman. 2006. Scale mismatches in social-ecological systems: causes, consequences, and solutions. Ecology and Society 11(1): 14. [online] URL: http://www.ecologyandsociety.org/vol11/ iss11/art14/

Dehue, B., C. Hamelinck, S.d. Lint, R. Archer, E. Garcia, and E.v.d. Heuvel. 2008. Sustainability reporting within the RTFO: framework report. Ecofys bv, Utrecht, The Netherlands. [online] URL: http://biomass.ucdavis.edu/ secure/materials/sustainability $\% 20$ committee/Ecofys $\%$ 20sustainabilityreporting\%20May07.pdf

Di Lucia, L. 2010. External governance and the EU policy for sustainable biofuels, the case of Mozambique. Energy Policy 38(11):7395-7403. http://dx.doi.org/10.1016/j.enpol.2010.08.015

European Union (EU). 2009. Directive 2009/28/EC of the European Parliament and of the Council on the promotion of biofuels and other renewable fuels for transport. Official Journal of the European Union L 140/16. European Commission, Brussels, Belgium.

Gibbons, M., C. Limoges, H. Nowotny, S. Schwartzman, P. Scott, and M. Trow. 1994. The new production of knowledge: the dynamics of science and research in contemporary societies. Sage, London, UK.

Gibson, C. C., E. Ostrom, and T. K. Ahn. 2000. The concept of scale and the human dimensions of global change: a survey.
Ecological Economics 32(2):217-239. http://dx.doi.org/10.1016/ S0921-8009(99)00092-0

Giller, K. E., C. Leeuwis, J. A. Andersson, W. Andriesse, A. Brouwer, P. Frost, P. Hebinck, I. Heitkönig, M. K. van Ittersum, N. Koning, R. Ruben, M. Slingerland, H. Udo, T. Veldkamp, C. van de Vijver, M. T. van Wijk, and P. Windmeijer. 2008. Competing claims on natural resources: what role for science? Ecology and Society 13(2): 34. [online] URL: http://www.ecologyandsociety.org/vol13/iss32/art34/

Government of Mozambique. 2009. Política e estratégia de biocombustíveis. Resolução 22/2009 [Biofuel policy and strategy. Resolution 22/2009], Maputo, Mozambique.

Gunderson, L. H., and C. S. Holling, editors. 2002. Panarchy: understanding transformations in human and natural systems. Island Press, Washington D.C., USA.

Hoppe, R. 2005. Rethinking the science-policy nexus: from knowledge utilization and science technology studies to types of boundary arrangements. Poiesis und Praxis 3(3):199-215. http://dx.doi.org/10.1007/s10202-005-0074-0

Jasanoff, S. 1990. The fifth branch: science advisors as policymakers.. Harvard University Press, Cambridge, Massachusetts, USA. http://dx.doi.org/10.1063/1.2810251

Keeney, D., and C. Nanninga. 2008. Biofuel and global biodiversity. Institute for Agriculture and Trade Policy (IATP). Minneapolis, Minnesota, USA.

Kok, K., and T. Veldkamp (editors). 2011a. Scale and Governance. Ecology and Society [online] URL: http://www. ecologyandsociety.org/issues/view.php?sf $=57$

Kok, K., and T. Veldkamp. 2011b. Scale and governance: conceptual considerations and practical implications. Ecology and Society 16(2): 23. [online] URL: http://www. ecologyandsociety.org/vol16/iss22/art23/

Mandemaker, M., M. Bakker, and J. Stoorvogel. 2011. The role of governance in agricultural expansion and intensification: a global study of arable agriculture. Ecology and Society 16(2): 8. http://dx.doi.org/10.5751/ES-04142-160208

Manson, S. M. 2008. Does scale exist? An epistemological scale continuum for complex human-environment systems. Geoforum 39(2):776-788. http://dx.doi.org/10.1016/j. geoforum.2006.09.010

McNie, E. C. 2007. Reconciling the supply of scientific information with user demands: an analysis of the problem and review of the literature. Environmental Science and Policy 10(1):17-18. http://dx.doi.org/10.1016/j.envsci.2006.10.004

Olsson, P., C. Folke, V. Galaz, T. Hahn, and L. Schultz. 2007. Enhancing the fit through adaptive co-management: creating and maintaining bridging functions for matching scales in the 
Kristianstads Vattenrike Biosphere Reserve, Sweden. Ecology and Society 12(1): 28. [online] URL: http://www. ecologyandsociety.org/vol12/iss21/art28/

Project Group Sustainable Production of Biomass. 2007. Testing framework for sustainable biomass. Interdepartmental Programme Management (IPM) Energy Transition, Government of The Netherlands, The Hague, The Netherlands. [online] URL: http://www.globalbioenergy.org/ uploads/media/0703 Sustainable Production of Sustainable production of biomass Cramer - Testing frameworkfor sustainable biomass 01.pdf

Roundtable on Sustainable Biofuels (RSB). 2008. Global principles and criteria for sustainable biofuels production. Version 0. Ecole Polytechnique Federale de Lausanne (EPFL) Energy Centre, Lausanne, Switzerland. [online] URL: http:// rsb.org/pdfs/standards/Version-Zero_RSB Std en.pdf

Schut, M., S. Bos, L. Machuama, and M. Slingerland. $2010 a$. Working towards sustainability. Learning experiences for sustainable biofuel strategies in Mozambique. Wageningen University and Research Centre, Wageningen, The Netherlands; Mozambique Centre for Agricultural Promotion (CEPAGRI), Maputo, Mozambique.

Schut, M., M. Slingerland, and A. Locke. 2010b. Biofuel developments in Mozambique. Update and analysis of policy, potential and reality. Energy Policy 38(9): 5151-5165. http:// dx.doi.org/http://dx.doi.org/10.1016/j.enpol.2010.04.048

Schut, M., C. Leeuwis, A. van Paassen, and A. Lerner. $2011 a$. Knowledge and innovation management in the policy debate on biofuel sustainability in Mozambique: what roles for researchers? Knowledge Management for Development Journal 7(1):45-64. http://dx.doi.org/http://dx.doi. org/10.1080/19474199.2011.593874

Schut, M., A. van Paassen, C. Leeuwis, S. Bos, W. Leonardo and A. Lerner. 2011b. Space for innovation for sustainable community-based biofuel production and use: lessons learned for policy from Nhambita community, Mozambique. Energy Policy 39(9):5116-5128. http://dx.doi.org/http://dx.doi.org/10.1016/ j.enpol.2011.05.053

Schut, M., A. Van Paassen, and C. Leeuwis. 2013. Beyond the research-policy interface. Boundary arrangements at research-stakeholder interfaces in the policy debate on biofuel sustainability in Mozambique. Environmental Science and Policy 27:91-102. http://dx.doi.org/10.1016/j.envsci.2012.10.007

Smeets, E., M. Junginger, A. Faaij, A. Walter, P. Dolzan, and W. Turkenburg. 2008. The sustainability of Brazilian ethanol: an assessment of the possibilities of certified production. Biomass and Bioenergy 32(8):781-813. http://dx.doi. org/10.1016/j.biombioe.2008.01.005
Smith, A., J.-P. Voß and J. Grin. 2010. Innovation studies and sustainability transitions: the allure of the multi-level perspective and its challenges. Research Policy 39(4):435448. http://dx.doi.org/10.1016/j.respol.2010.01.023

Termeer, C. J .A. M., A. Dewulf, and M. van Lieshout. 2010. Disentangling scale approaches in governance research: comparing monocentric, multilevel, and adapative governance. Ecology and Society 15(4): 29. [online] URL: http://www. ecologyandsociety.org/vol15/iss24/art29/

Turnhout, E., and S. Boonman-Berson. 2011. Databases, scaling practices, and the globalization of biodiversity. Ecology and Society 16(1): 35. [online] URL: http://www. ecologyandsociety.org/vol16/iss31/art35/

van Dam, J., M. Junginger, A. Faaij, I. Jürgens, G. Best, and U. Fritsche. 2008. Overview of recent developments in sustainable biomass certification. Biomass and Bioenergy 32 (8):749-780. http://dx.doi.org/10.1016/j.biombioe.2008.01.018

van der Veen, A., and G. Tagel. 2011. Effect of policy interventions on food security in Tigray, northern Ethiopia. Ecology and Society 16(1): 18. [online] URL: http://www. ecologyandsociety.org/vol16/iss11/art18/

van Lieshout, M., A. Dewulf, N. Aarts, and C. J. A. M. Termeer. 2011. Do scale frames matter? Scale frame mismatches in the decision making process about a "mega farm" in a small Dutch village. Ecology and Society 16(1): 38. [online] URL: http://www.ecologyandsociety.org/vol16/ iss31/art38/

Veldkamp, T., N. Polman, S. Reinhard, and M. Slingerland. 2011. From scaling to governance of the land system: bridging ecological and economic perspectives. Ecology and Society 16(1): 18. [online] URL: http://www.ecologyandsociety.org/ vol16/iss11/art11/

Woods, J., and R. Diaz-Chavez. 2007. The environmental certification of biofuels. Pages 189-209 in Biofuels: linking support to performance. Round table 138. Organisation for Economic Co-operation and Development (OECD), International Transport Forum and Faculty of Natural Sciences, Imperial College London, London, UK. http://dx. doi.org/10.1787/9789282101803-7-en

World Bank. 2009. Mozambique-country brief. [online] URL: http://go.worldbank.org/70UK6S1X30 


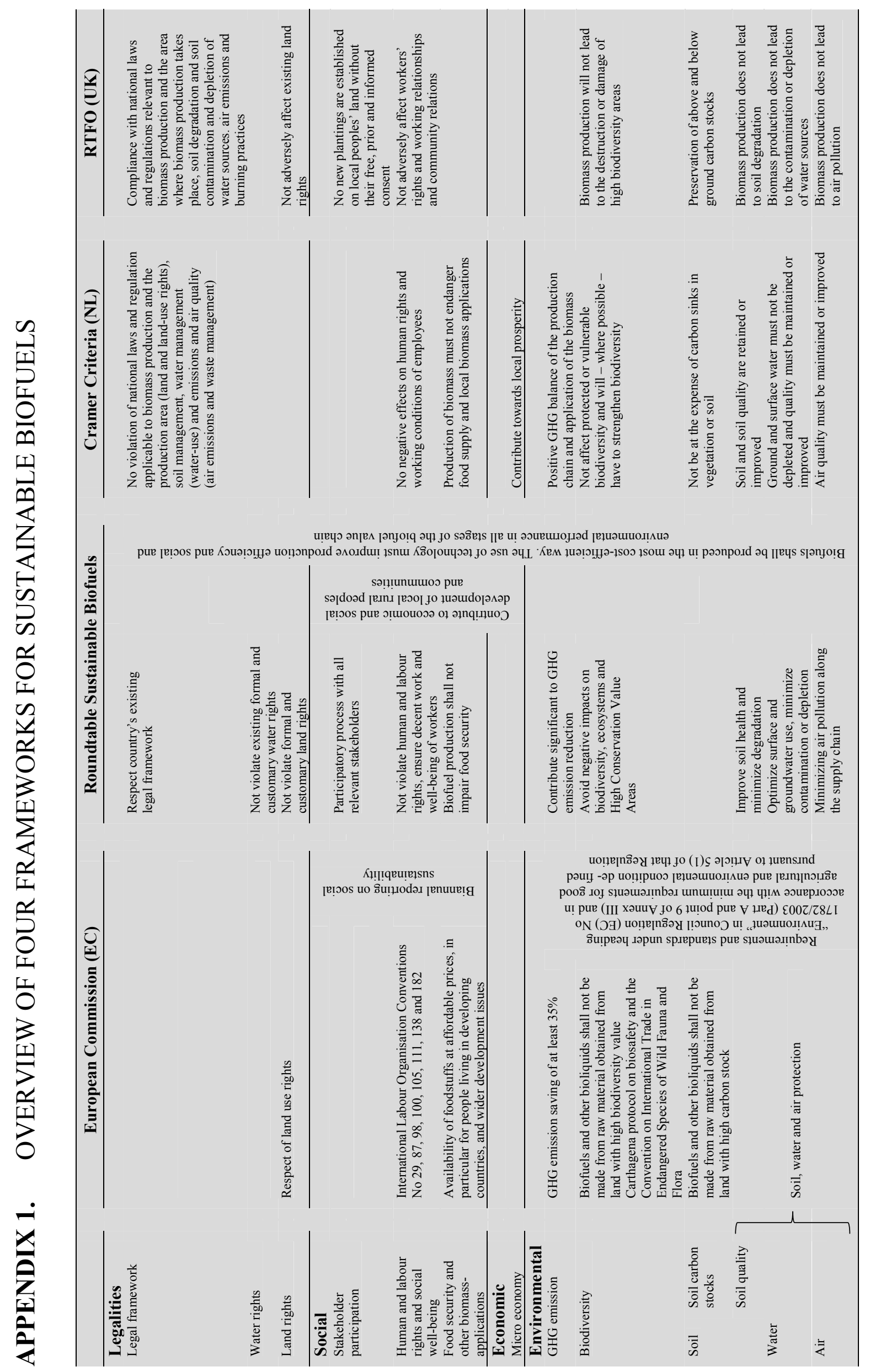




\section{Notes with Appendix 1}

The appendix includes four frameworks for sustainable biofuels:

1. The EU policy framework for sustainable biomass production (Directive 2009/28/EC) (Council of the European Union 2008). Under Article 15, the draft Directive proposes seven sustainability criteria for biofuels and other bioliquids. Criteria 1, 6 and 7 refer to the administrative terms, conditions and consequences of demonstrating compliance with Article 15 of the Directive and have therefore not been included in the scheme. Criteria 5 and 5a were so widely formulated, that the authors decided to subdivide the several issues addressed. The final version of Directive 2009/28/EC refers to Council Regulation (EC) 73/2009 of 19 January 2009 that repealed Council Regulation (EC) No. $1782 / 2003$.

2. The Roundtable on Sustainable Biofuels (RSB), a multi-stakeholder platform that developed a voluntary, third-party certification system for biofuel sustainability (Roundtable on Sustainable Biofuels 2008). Version 0 contains 12 principles of which some are subdivided. The 12 principles have been used in Appendix 1.

3. The Dutch Cramer Criteria; a biofuel sustainability framework designed for biomass that is produced, processed and used in the Netherlands (NL) or subsidized by the Netherlands (Project Group Sustainable Production of Biomass 2007). This framework contains six themes operationalized in nine principles. The nine principles have been used in Appendix 1.

4. The UK Renewable Transport Fuels Obligation (RTFO) including sustainability criteria and indicators (Dehue et al. 2008). Seven principles, subdivided in several criterion and indicators. The seven principles have been used in Appendix 1.

As - during the study - the EU and RSB frameworks were in the process of being developed, we studied the policy proposal by the Counsel of the European Union (17086/08 of 11 December 2008), and Version 0 of the RSB. 
Appendix 2. Introduction to Forest Stewardship Council (FSC), Global Partnership for Good Agricultural Practice (GLOBALG.A.P.), and Fairtrade International.

Forest Stewardship Council (FSC) is an independent, non-governmental, non-profit organisation that promotes responsible forest management. FSC is an association of members consisting of a diverse group of representatives from environmental and social groups, the timber trade, indigenous peoples' organisations, responsible corporations, community forestry groups and forest product certification organizations from around the world. In Mozambique, two companies are FSC certified.

Global Partnership for Good Agricultural Practice (GLOBALG.A.P.) certification is a voluntary system driven by the private sector that sets standards for the certification of agricultural products. In Mozambique, there is currently one company with GLOBALG.A.P. certification. We know of two companies that are in the process of becoming GLOBALG.A.P. certified.

Fairtrade International works to improve market access and trading conditions for small-scale producers and plantation workers. Fairtrade organisations pay a minimum guaranteed price to the producer, plus a Fairtrade premium, which must be used for organisational strengthening and community development (Coulibaly and Liu 2006:25). Fairtrade Labelling Organizations International (FLO) is the worldwide umbrella organisation for Fairtrade standard setting and certification. In Mozambique, a few peanut and cashew producers are Fairtrade certified. 